\title{
Potent Phagocytic Activity Discriminates Metastatic and Primary Human Malignant Melanomas: A Key Role of Ezrin
}

\author{
Luana Lugini, Francesco Lozupone, Paola Matarrese, Cristina Funaro, \\ Francesca Luciani, Walter Malorni, Licia Rivoltini, Chiara Castelli, Antonella Tinari, \\ Adriano Piris, Giorgio Parmiani, and Stefano Fais
}

Laboratories of Immunology (LL, FLo, CF, FLu, SF) and Ultrastructures (PM, WM, AT), Istituto Superiore di Sanità, Rome, and Unit of Immunotherapy of Human Tumors (LR, CC, AP, GP), Istituto Nazionale dei Tumori, Milan, Italy

SUMMARY: Features of phagocytosis have been observed in human tumors, but the phagocytic apparatus of tumor cells and the mechanism(s) underlying this phenomenon have yet to be defined. To address the phenomenon of phagocytosis, its underlying mechanism(s), and its possible role in tumor biology, we used human melanoma cells as a prototypic model. Our results showed that a process of phagocytosis of apoptotic cells occurs in vivo in human melanoma. This finding was consistent with evidence that human melanoma cells in vitro express all of the known lysosomal and phagocytic markers on their cytoplasmic vesicles and that a process of phagocytosis occurs in these vesicles. However, exclusively human melanoma cells deriving from metastatic lesions possess an efficient phagocytic machinery responsible for a macrophage-like activity against latex beads, yeast, and apoptotic cells of different origins, which was comparable to that of human primary macrophages. Moreover, the actin-binding protein ezrin was expressed on phagocytic vacuoles of melanoma cells and of cells deriving from a human adenocarcinoma; both treatment with cytochalasin B and specific inhibition of ezrin synthesis strongly affected the phagocytic activity of melanoma cells. This suggests that the association with the actin cytoskeleton is a crucial requirement for the development of this phenomenon. Hence our data provide evidence for a potent phagocytic activity exerted by metastatic melanoma cells possibly involved in determining the level of aggressiveness of human melanoma. This suggests that the assessment of phagocytic activity may be exploited as a new tool to evaluate the malignancy of human melanoma. Moreover, our data suggest that gene therapy or drug treatments aimed at inhibiting actin assembly to the phagosomal membranes may be proposed as a new strategy for the control of tumor aggressiveness. (Lab Invest 2003, 83:1555-1567).

$T$ he phagocytic-like behavior of tumor cells was first observed a century ago (Steinhaus, 1891) and confirmed by many other authors who described phagocytic activity of various murine and human tumor cells against both dead cells and undefined particles (DeSimone et al, 1980; Marin-Padilla, 1977). More recently, many morphologic aspects associated with phagocytosis have been identified in tumors (Banerjee and Harris, 2000), and the phagocytic-like activity of these cells has been associated with invasiveness (Coopman et al, 1998; Montcourrier et al, 1994). Moreover, other histopathologic signs of tumor malignancy, recalling an in vivo phagocytic-like behavior of tumor cells, have been described. Between the above mentioned signs there are the so-called "signet-ring cells," mostly typical of adenocarcinoma (Kuroda et al, 1999) and characterized by the presence of intracytoplasmic mucin displacing the nu-

\section{DOI: 10.1097/01.LAB.0000098425.03006.42}

Received April 8, 2003.

This work was supported by grants from AIRC (Associazione Italiana per la Ricerca sul Cancro), Milano, and from the Italian Ministry of Health, Rome. Address reprint requests to: Dr. S. Fais, Laboratory of Immunology, Istituto Superiore di Sanita; 00161 Rome, Italy.E-mail:fais@iss.it cleus. However, signet-ring cells can also be found in nonepithelial tumors, such as malignant lymphomas and melanomas (Tsang et al, 1992). The nature of these cells, particularly in nonepithelial tumors, is not known, but it is conceivable that an aberrant scavenging activity underlies this phenomenon (Banerjee and Harris, 2000; Kuroda et al, 1999). Altogether these reports suggest that active phagocytosis occurs in human tumor cells, but the phagocytic apparatus of tumor cells has never been defined and the mechanism(s) underlying this phenomenon have not been investigated.

To address the phenomenon of phagocytosis, its underlying mechanism(s), and its possible role in tumor aggressiveness, we used human melanoma cells as a prototypic model. In fact, it has been shown that melanosomes are specialized lysosomal-like organelles (Dell'Angelica et al, 2000), able to fuse with phagosomes (Le Poole et al, 1993). This evidence is supported by the presence of an acidic pH, hydrolases, and acidic phosphatases in these organelles, as well as by their expression of some lysosomal-associated proteins (Lamp) (Dell'Angelica et al, 2000). Moreover, during melanogenesis, melanoma cells (similar to professional phagocytes) increase their amount of tyrosinase-produced superoxide anion (Koga et al, 1992). 

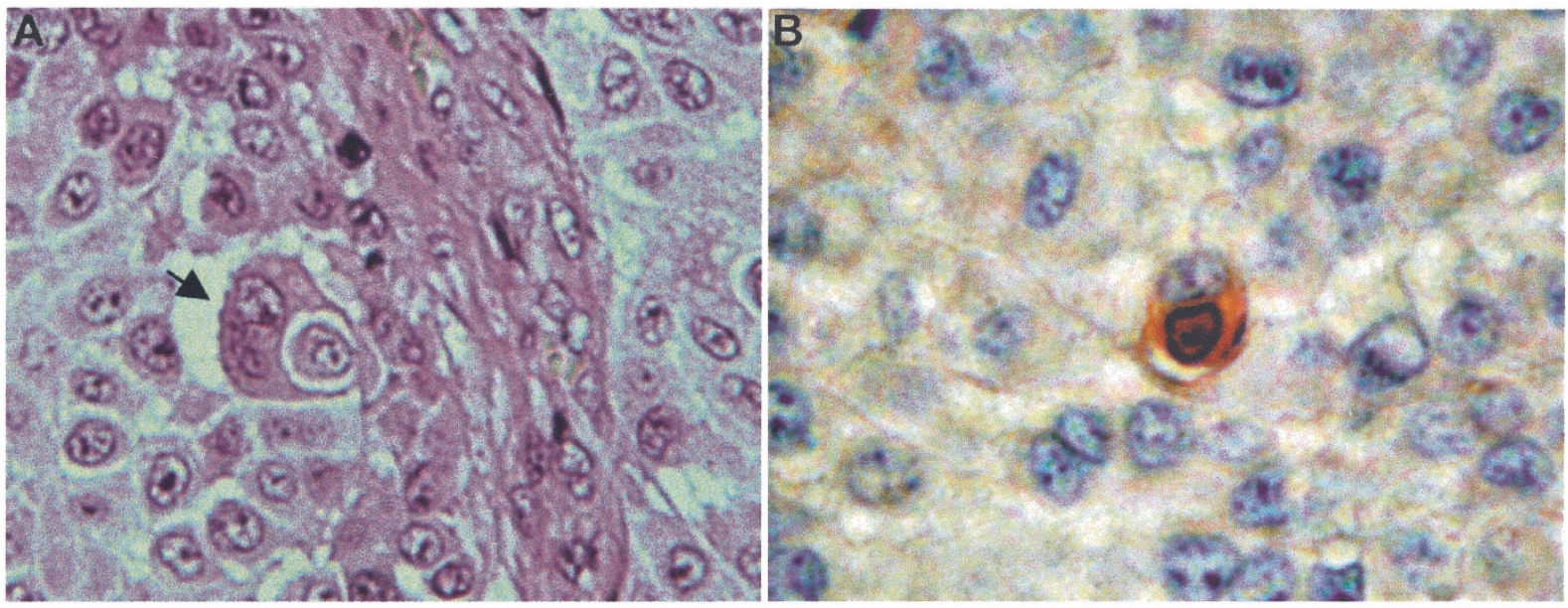

\section{Figure 1.}

In vivo autophagocytosis in melanoma tumors. A, Histologic preparation of a metastatic melanoma sample. A large epithelioid tumor cell contains an (apparently) intact tumor cell (arrow). The nuclear features of the "ingested" cell are the same as those present in the rest of the sample. [Hematoxylin and eosin (HE) magnification, $\times 350$ ]. B, Histologic preparation of a metastatic melanoma sample. In the center of the field, a Tunel-positive (apoptotic) cell within a bigger, Tunel-negative cell is shown. (HE: magnification, $\times 350)$.

Some recent data, obtained in murine macrophages, suggest a crucial role of the actin cytoskeleton in different phases of the phagocytosis process, such as actin assembly on secondary phagosome membranes (Defacque et al, 2000) and vesicular traf- ficking (Tauton, 2001), both caused by an association between cellular membranes and the actin cytoskeleton through ERM (ezrin, radixin, and moesin). Moreover, we have recently shown that the bacterial-toxininduced activation of some actin-regulatory proteins

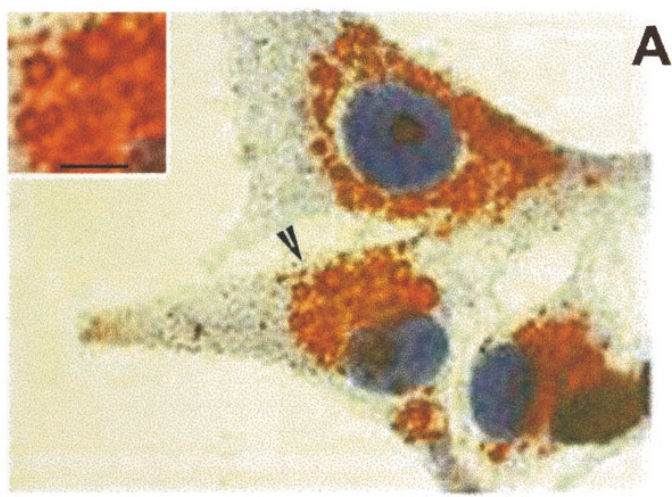

A
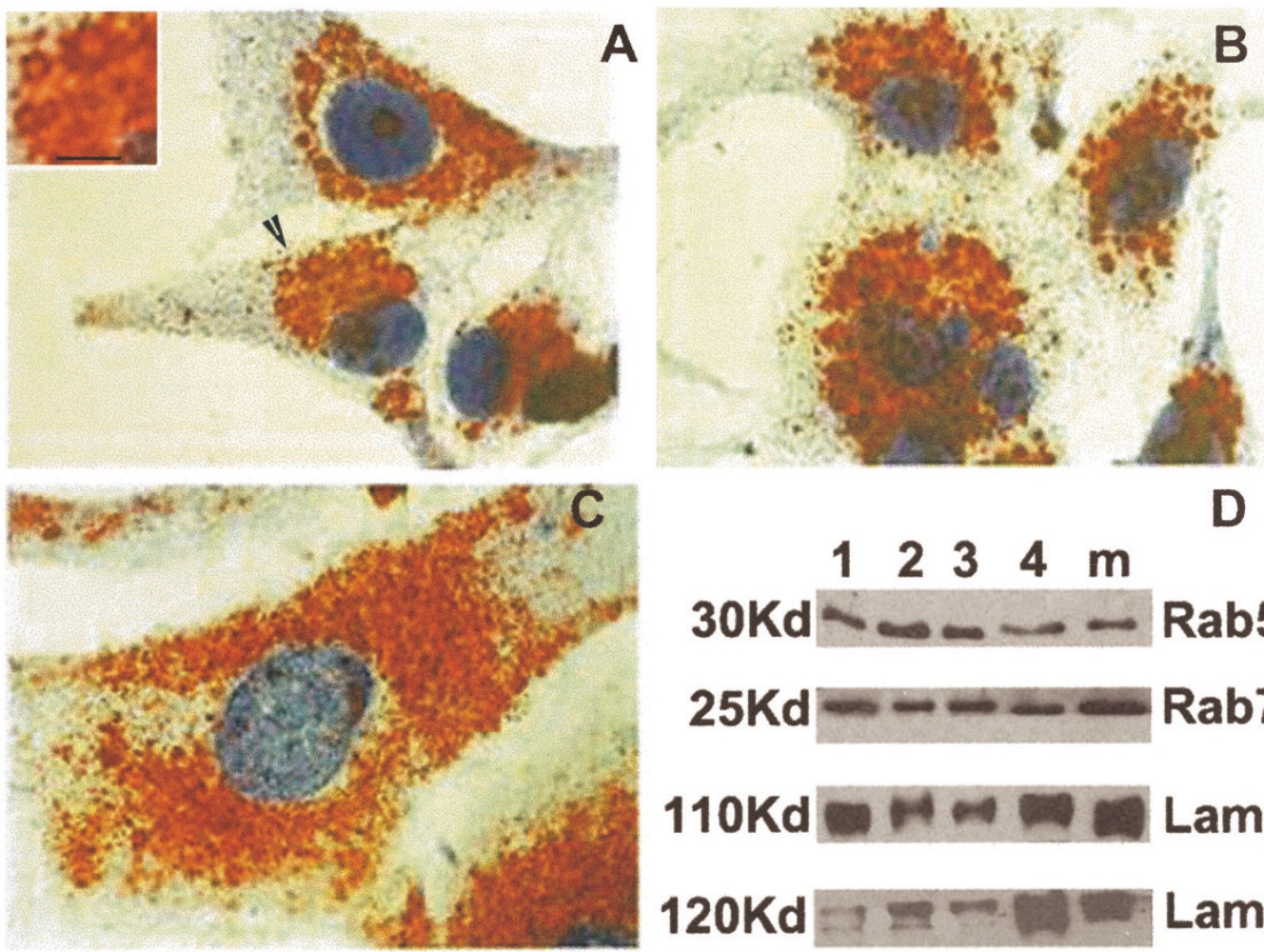

D

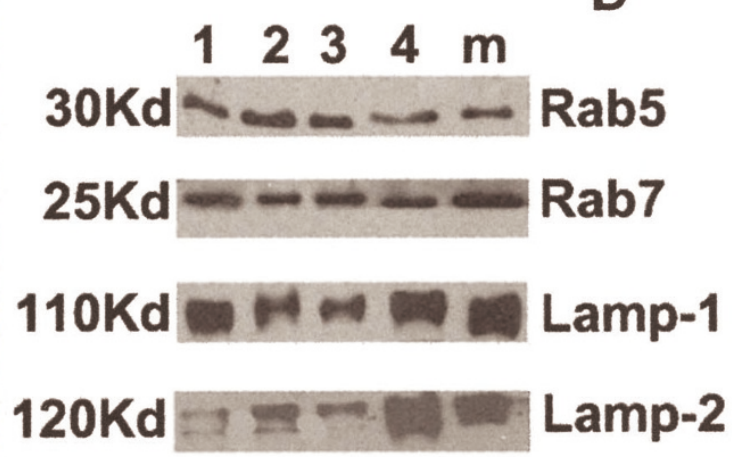

Figure 2.

Expression and distribution of phagocytic markers in melanoma cells. Lysosomal-associated protein-1 (Lamp-1) (A), Rab7 (B), and CD68 (C) stainings in a representative melanoma cell line. The inset in A shows an electronic magnification $(\times 3500)$ of the area indicated by the arrowhead $($ bar $=0.5 \mu \mathrm{m})$. Immunophenotyping of fixed cells was performed using the peroxidase anti-peroxidase (PAP) method. AEC was used as chromogen and Mayer's hematoxylin for the counterstaining. Final magnification, $\times 1500$. (D) Western blot analysis of Rab5, Rab7, Lamp-1, and Lamp-2 proteins on total protein extract of four (1, 2, 3, 4) melanomas as compared with human primary macrophages $(m)$. The relative molecular weights are indicated. 
(ie, $\rho$-GTPase) results in the induction of a genuine phagocytic activity in a human epithelial cell line (Fiorentini et al, 2001), further suggesting a crucial role of the actin cytoskeleton in this process.

On the basis of these considerations, the goals of this study were as follows: (i) to evaluate the in vivo occurrence of phagocytosis in human melanoma; (ii) to assess the presence of phagocytosis in human melanoma cells and characterize the phagocytic machinery of melanoma cells and its possible relationship with the phagocytic activity; (iii) to evaluate both the ability of melanoma cells to ingest and phagocyte amorphic material (latex beads), yeasts, and dead cells and the relationships between phagocytic activity and the malignancy of melanoma; and (iv) to understand the key mechanism(s) underlying this phagocytic activity. Our results showed that human melanoma cells deriving from metastatic lesions, but not from primary tumors, possess an efficient phagocytic machinery responsible for a macrophage-like activity against latex beads, yeast, and apoptotic cells and that ezrin holds a key role in the phagocytic activity of metastatic melanoma cells.

\section{Results}

\section{In Vivo Occurrence of Phagocytic Behavior in Human Melanoma}

We first investigated the occurrence of phagocytosis in samples of human melanomas. Histologic analysis of melanoma tumors revealed the presence of in vivo phagocytosis in human melanoma (Fig. 1A). Moreover, immunohistochemistry showed the presence of apoptotic (Tunel positive) cells within cytoplasmic vacuoles of in vivo phagocyting cells (Fig. 1B). This first set of results showed that phagocytic activity against apoptotic cells occurred in vivo in human malignant melanoma.

\section{Expression and Distribution of Lysosomal Proteins and Spontaneous Phagocytic Activity of Human Melanoma Cells}

Thus, we investigated the expression of phagocytic markers in human melanoma cells as compared with monocyte-derived macrophages. The results showed that $100 \%$ of melanoma cells stained for all of the endocytic (Rab5), lysosomal (Lamp-1, Lamp-2, CD63), and phagocytic markers (CD68 and Rab7) tested (Fig. 2). Moreover, the immunocytochemical analysis showed that the staining for the phagocytic markers, such as Lamp-1, Rab7, and CD68 (Fig. 2, A, B, and C, respectively), was mostly localized on perinuclear vesicles measuring 100 to $300 \mathrm{~nm}$ (Fig. 2A, inset) (the images were electronically acquired by a camera scanner for light microscopy application and electronically elaborated through a modular image processing and analysis system; see "Materials and Methods"). This was consistent with the distribution of the same proteins in professional macrophages (data not shown). The immunocytochemical data were consistent with the Western blot analysis inasmuch as both confirmed the expression of the phagocytic markers by melanoma cells and showed comparable molecular weights of these proteins between melanoma cells and professional phagocytes (Fig. 2D). Figure 3 (A to D) shows additional findings suggesting a possible phagocytic sequence of the ingested autologous cells (early contact and internalization: Figure 3, A and B; and total degradation: Fig. 3, C and D), occurring in vacuoles stained for a phagocytic marker (ie, CD68). These results clearly show that the phagocytic markers were mostly localized on vacuoles containing cells in various stages of degradation, suggesting the occurrence of a genuine phagocytosis in human melanoma cell cultures. Moreover, these data definitively demonstrate that a genuine macrophage-like phagocytic behavior underlies the frequent in vivo findings of autophagocytic figures in histopathologic specimens of human melanoma (Banerjee and Harris, 2000).

\section{In Vitro Phagocytic Activity of Human Melanoma Cells}

To assess the phagocytic activity of human melanoma cells, we measured the ability of 8 primary and 11 metastatic human melanoma cell lines to ingest either latex beads or apoptotic cells, as compared with human primary macrophages. In the first set of experiments, latex beads were added to human melanoma cell lines or human primary macrophages. After 2 hours the cultures were stopped and analyzed by immunocytochemistry for the expression and distribution of the lysosomal marker Lamp-1. Melanoma cell lines derived from either primary or metastatic lesions were analyzed to investigate the potential role of this phenomenon in tumor aggressiveness. The results showed that all of the melanoma cells derived from metastatic lesions absorbed the latex beads within 2 hours after their addition to the cell cultures (Fig. 4, B to $\mathrm{D})$, at levels comparable to that of professional phagocytes (Fig. 4A). Notably, cell lines derived from primary melanomas did not absorb the particles (not shown). Of interest, as shown in Figure 4, the phagocytic markers were mostly distributed on the membrane of the vesicles containing latex beads. We quantified the level of phagocytosis by calculating the phagocytic index (P.I.; see "Materials and Methods") in the melanoma cell lines as compared with human primary macrophages. The results demonstrated a comparable P.I. between human primary macrophages from different donors and melanoma cell lines derived from metastatic lesions, whereas melanoma cells from primary tumors did not show phagocytosis (Table 1).

In further evaluating the phagocytic activity of melanoma cells, we cultured either melanoma cells or macrophages with apoptotic cells of different origins (ie, primary melanoma, metastatic melanoma, human primary monocytes, macrophages, dendritic cells, lymphoblastoid, and promonocytic cells), using the same method as that for latex beads. The data were highly consistent with those obtained using latex beads, showing that the various melanoma cell lines derived from metastatic lesions, as well as the single 

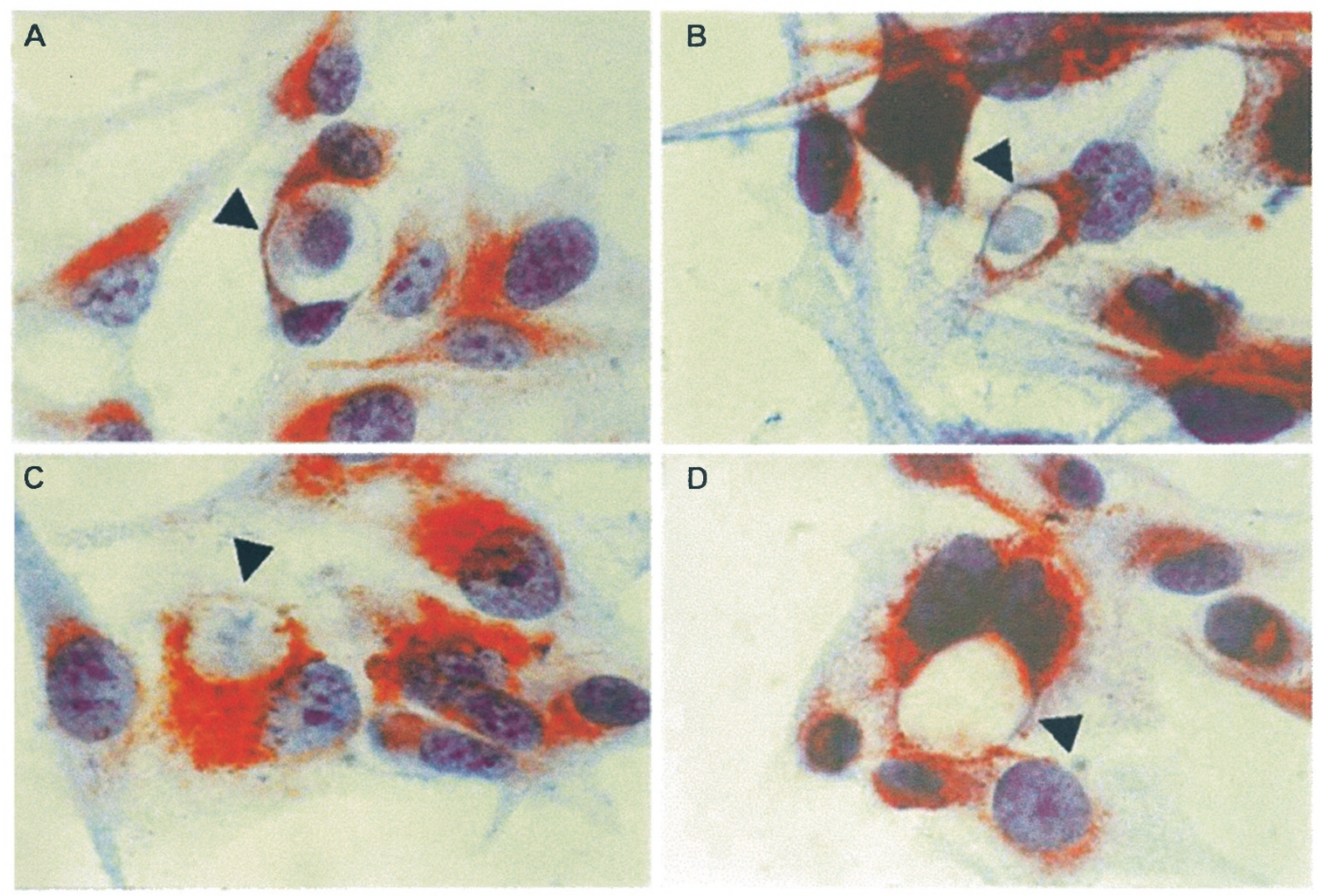

Figure 3.

Phagocytic markers and autophagocytosis in melanoma cells. A to D, Possible sequence of an autophagocytic process occurring in homotypic culture of human melanoma cells: early internalization $(A)$ and progressive degradation ( $B$ to $D$ ) of the internalized cell. The red staining is for the phagocytic marker CD68. Immunophenotyping of fixed cells was performed using the PAP method. AEC was used as chromogen and Mayer's hematoxylin for the counterstaining. Arrowheads indicate the vacuoles containing the apoptotic cells in various states of degradation. Final magnification, $\times 2500$.

donor-derived human primary macrophages, exerted variable levels of apoptotic cell phagocytosis, whereas cell lines from primary tumors did not show detectable phagocytic activity (Table 1). Moreover, because of the larger cellular size, melanoma cells in some cases were able to internalize up to 20 apoptotic particles (Fig. 4, G and H), whereas the number of apoptotic cells absorbed from human primary macrophages ranged from two to seven per cell (Fig. 4, E and F). The phagocytic activity of melanoma cells against apoptotic cells was also evaluated by electron microscopy. The results showed the presence of the apoptotic cells within well-defined cytoplasmic vacuoles (Fig. 5A), in which ingested cells underwent degradation (Fig. 5B). Thus, as suggested by immunocytochemical and electron microscopy appearance, a genuine phagocytic process occurred in human melanoma cells, leading to endocytosis and progressive degradation of the ingested apoptotic cells.

To further quantify the phagocytic activity of melanoma cells, we modified a previously described method (Kaminski et al, 1985) that exploits Congo Red-stained yeast as targets of phagocytosis. In evaluating melanoma cell phagocytosis toward the stained yeast, we used both spectrophotometric and FACS analysis. The analysis by the spectrophotometer was markedly impaired by the baseline absorbance at $510 \mathrm{~nm}$ of melanoma cells, mostly because of the variable content of melanin (not shown). Thus, we used the FACS analyses to reliably measure the level of internalization of the stained yeast within the melanoma cells at $1.5,2.5$, and 3.5 hours after the addition of the yeasts. We found that, similar to human primary macrophages, each melanoma cell line derived from metastatic lesions was able to internalize yeasts and that this phagocytic activity increased in a timedependent manner (Fig. 6B). Again melanoma cells derived from primary tumors did not show yeast internalization (Fig. 6B). Both human peripheral blood lymphocytes and a murine fibroblast cell line (3T3), used as negative controls, failed to ingest the Congo Red-stained yeasts (not shown). Our results (obtained by analyzing only cells included in "region 1"; Fig. 6A) demonstrated that most of the fluorescence intensity observed in melanoma cells was a result of internalized yeast particles. In fact, when a phagocytic test was performed at $4^{\circ} \mathrm{C}$ (a temperature that inhibits internalization of yeasts but not their adhesion on the cell surface), a small percentage of red-positive melanoma cells (from $0.5 \pm 0.2$ to $1.2 \pm 0.9 \%$ ) was revealed.

We thus performed time-course experiments with the purpose of comparing the phagocytic activity of primary and metastatic melanoma cells at early (1-3 hours) and 

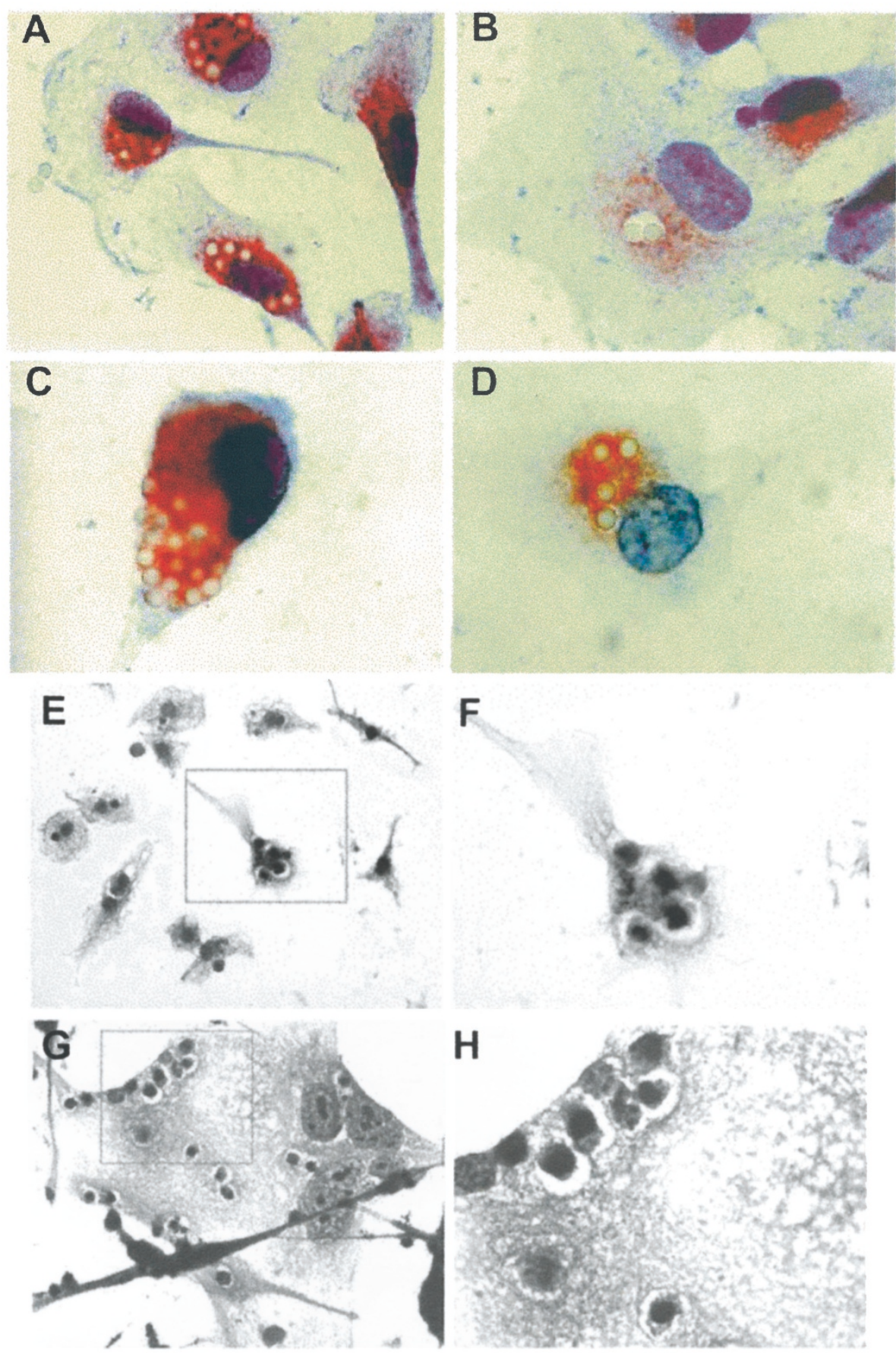

\section{Figure 4.}

Latex beads and apoptotic cell endocytosis and their relationship to phagocytic markers in human melanoma cells. Internalization of latex beads in well-defined cytoplasmic vacuoles of human macrophages (A) and three human melanoma cell lines (B-D) is shown. Note the staining for Lamp-1 that nicely outlines the bead-containing vacuoles. Immunophenotyping of fixed cells was performed using the PAP method. AEC was used as chromogen and Mayer's hematoxylin for the counterstaining. The internalization of apoptotic cells by human primary macrophages (E) and melanoma cells $(G)$ is shown. $F$ and $H$ are electronically obtained magnifications of the insets of $\mathrm{E}$ and $\mathrm{G}$, respectively. Mayer's hematoxylin counterstaining. Final magnifications: $A-D$ and $F-H, \times 2500 ; E-G$, $\times 1500$.

late (24-48 hours) time points. The results summarized in Figure 7 show that melanoma cells derived from metastatic tumors increased their phagocytic activity over time, reaching impressive values at 48 hours of culture, whereas melanoma cells from primary melanomas showed a slight but detectable phagocytic activity only at the later time points. Notably, data obtained with the FACS analysis of ingested Congo Red-stained yeast
(Fig. 7A) were highly consistent with those obtained with latex beads (Fig. 7B).

\section{The Role of Cytoskeleton and Ezrin in the Phagocytic Activity of Melanoma Cells}

On the basis of previous studies showing a crucial role of the actin cytoskeleton in the phagocytic function of 
Table 1. Phagocytic Activity of Melanoma Cell Lines and Macrophages

\begin{tabular}{lccc}
\hline & P. Mel. (8) & M. Mel. (11) & Macrophages (8) \\
\hline Beads & 0 & $24 \pm 12.3$ & $30 \pm 7.2$ \\
A.B. mel & 0 & $29 \pm 15.8$ & $33 \pm 7.8$ \\
A.B. U937 & 0 & $23 \pm 11.6$ & $28 \pm 6.1$ \\
A.B. mono & 0 & $25 \pm 12.2$ & $29 \pm 7.2$ \\
A.B. macr & 0 & $27 \pm 14.4$ & $31 \pm 6.9$ \\
A.B. D.C. & 0 & $24 \pm 11.9$ & $29 \pm 7.6$ \\
A.B. lymp & 0 & $30 \pm 12$ & $34 \pm 7.3$ \\
\hline
\end{tabular}

Phagocytic activity against latex beads and apoptotic bodies (A.B.) from various cell sources, such as melanoma cells (mel), promonocytic cells (U937), primary monocytes (mono), adherence-derived macrophages (macr), monocyte-derived dendritic cells (D.C.), and lymphoid cells (lymp) (see "Materials and Methods"). The phagocytic activity was assessed by phagocytic index (P.I.) Numbers are mean \pm SEM of 20 different experiments.
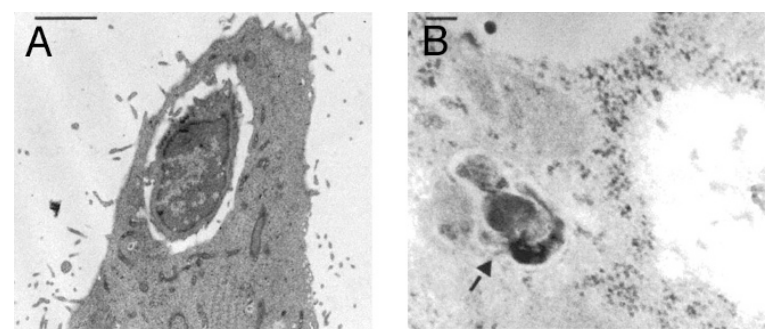

Figure 5.

Electron microscopy analysis of phagocytic-like activity in human melanoma cells. A, Transmission electron microscopy (TEM) micrograph showing the early engulfment of a U937 cell undergoing apoptosis in a big vacuole beneath the membrane of a melanoma cell. Note that the apoptotic cell does not show features of degradation at this stage $($ bar $=2 \mu \mathrm{m})$. B, TEM micrograph showing an apoptotic cell undergoing partial degradation inside an intracytoplasmic vacuole of a melanoma cell. The arrow points to the phagocytic vacuole, where the inner and the outer membrane sites are clearly detectable. Note the chromatinic structures of the apoptotic cell clearly visible within the vacuole (bar $=0.2 \mu \mathrm{m})$.

professional phagocytes, and in particular of the proteins that link the membrane of phagosomes to actin (ie, ERM) (Defacque et al, 2000), we explored the possible involvement of ERM in the phagocytic activity of melanoma cells. We first investigated the involvement of actin and ERM in the phagocytic activity of melanoma cells. We treated melanoma cells with (i) a noncytotoxic concentration ( $0.2 \mu \mathrm{M}$ per 1 hour) of CytB and (ii) antisense phosphorothioate oligonucleotides (PONs) complementary to the internal sequence of the coding regions of human ERM (Luciani et al, 2002; Parlato et al, 2000), assaying phagocytosis by FACS analysis. We preliminarily assessed the effect of the various PONs on ERM protein synthesis. Consistent with previous experiments performed on human cell lines of different origin (Luciani et al, 2002), the 60 -hour treatment of melanoma cells induced a marked reduction of the ERM protein levels (Fig. 8A, left panel), without detectable cytotoxic effects (not shown), whereas the 72-hour treatment, although abolishing ERM protein synthesis (Fig. 8A, right panel), showed significant cytotoxic effects (not shown). On the basis of these results, we treated melanoma cells with the various PONs for 60 hours, to avoid the toxic effects shown with long-lasting treatment with the ERM antisense PONs. The results showed that treatment with CytB completely abolished the phagocytic activity of metastatic melanoma (Fig. 8B, upper panels). The results of the pretreatment with ERM antisense PONs showed that only the ezrin antisense PONs and a mix of all of the ERM antisense PONs (Fig. $8 \mathrm{~B}$, central panels) markedly inhibited the phagocytic activity of metastatic melanoma; the moesin antisense PONs only slightly inhibited this activity of melanoma cells (Fig. 8, lower panels). The ERM sense PONs, used as an internal control, did not affect the phagocytic function of melanoma cells (Fig. 8B, lower panels).

To further investigate the involvement of ezrin in the phagocytic activity of melanoma cells, we evaluated the ezrin distribution in melanoma cells undergoing phagocytosis of plastic beads or apoptotic cells. The results showed that ezrin was clearly expressed on phagocytic vacuoles containing the beads (Fig. 9A). Moreover, we performed triple fluorescence experiments showing that ezrin was coexpressed with lysosomal antigens on phagocytic vacuoles of melanoma cells containing apoptotic cells (Fig. 9B). In the same experiments, we compared the ezrin distribution in melanoma cells undergoing phagocytosis to that occurring in human adenocarcinoma cells. The results showed a lysosomal antigen and ezrin distribution on the phagocytic vacuoles of adenocarcinoma cells similar to that of melanoma cells (Fig. 9C).

\section{Discussion}

This study shows that human melanoma cells, similarly to professional phagocytes, clearly expressed both lysosomal-associated proteins (LAMP-1, LAMP-2, CD68, CD63) and markers of early endosomes (Rab5) and late phagosomes (Rab7). These markers clearly outline macrophage-like phagosomes, in which a progressive degradation of autologous nuclei does occur, strongly suggesting that a genuine phagocytosis underlies the in vivo phagocytosis we have shown in melanoma tumors. This supports a previous finding showing features of autophagocytosis in human melanomas (Banerjee and Harris, 2000). Our study definitively demonstrates that both the presence of a complete phagocytic machinery and the phagocytosis are consistent with the ability of melanoma cells to exert a macrophage-like activity. In fact, only melanoma cells derived from metastatic lesions were able to internalize latex beads and progressively digest yeasts and apoptotic cells.

We further showed that the actin cytoskeleton had a key role in the phagocytic activity of melanoma cells. In fact, ezrin was coexpressed with lysosomal markers on phagosomes of melanoma cells, and treatments with either cytochalasin or antisense oligonucleotides against ERMs, a family of proteins that link actin to the cell membranes (Bretscher et al, 1997; Gautreau et al, 2002), markedly inhibited the phagocytic activity of melanoma cells. In particular, we showed that ezrin was the most involved protein in this process. This last 
A
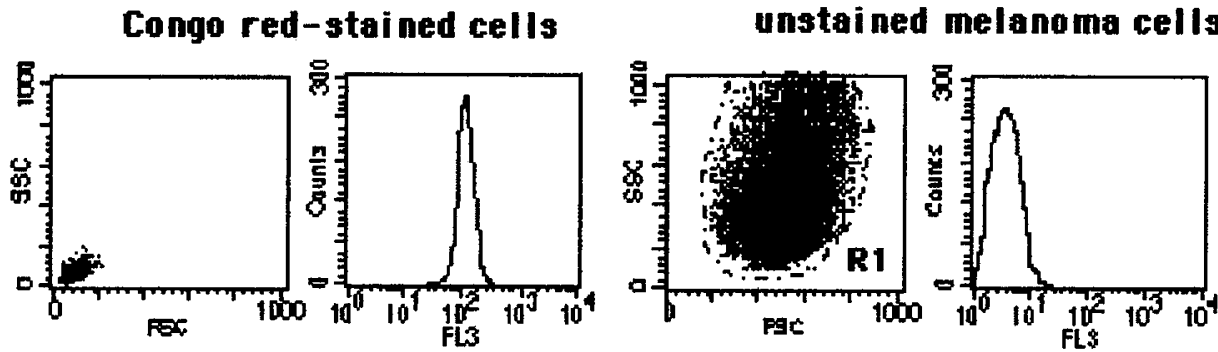

$\mathbf{B}$
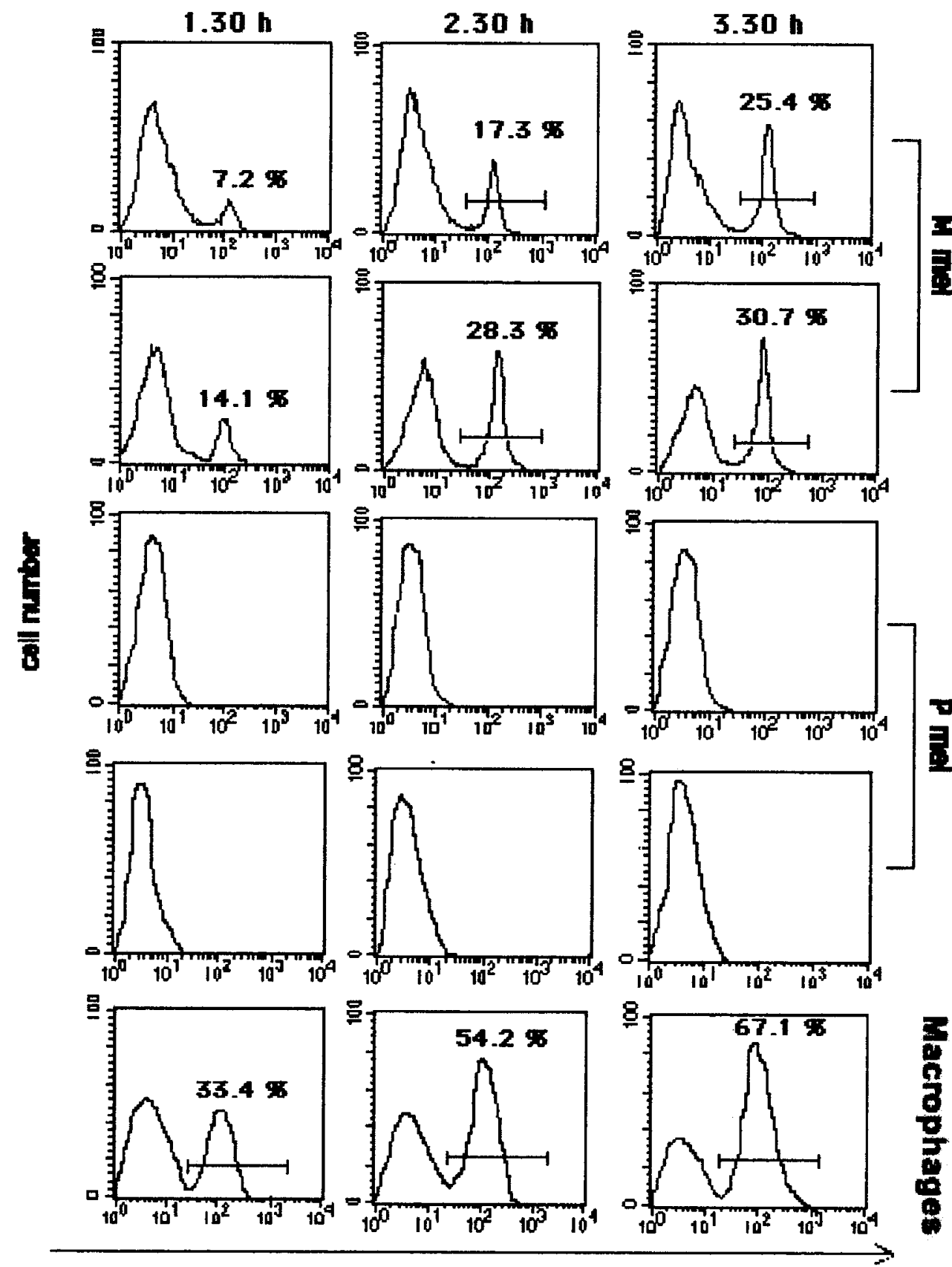

red fluorescence

Figure 6.

Melanoma cell phagocytic activity against yeast cells as evaluated by FACS. Row A, Physic parameters and red fluorescence emission of Congo Red-stained yeast particles and unstained melanoma cells. Row $B$, Analysis of cell fluorescence emission, performed only in the cells included in region R1 to exclude yeast particles not associated with melanoma cells. Numbers reported in the figure represent the percentage of two melanoma cell lines derived from metastatic lesions ( $M$ men), two melanoma cell lines derived from primary lesions $(P \mathrm{me})$, and human primary macrophages (macrophages) as positive controls, containing the Congo Red-stained yeast particles. 


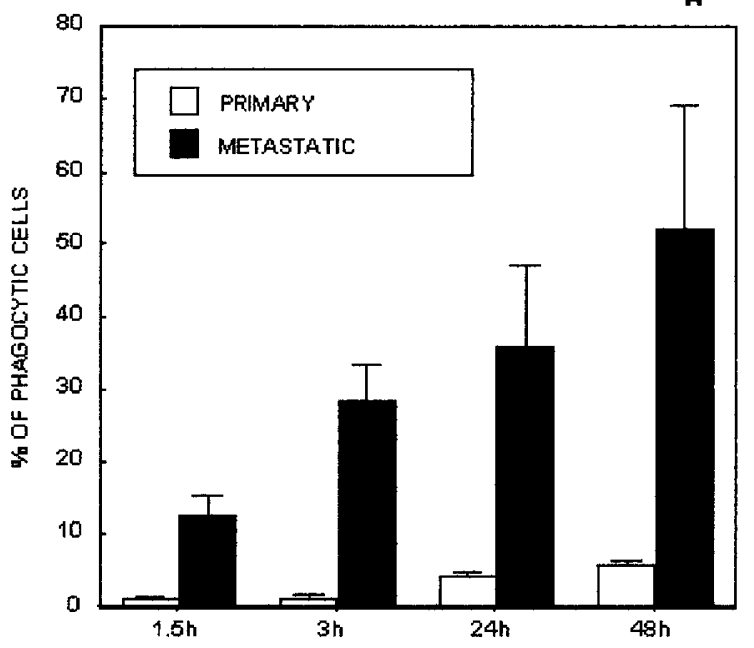

B

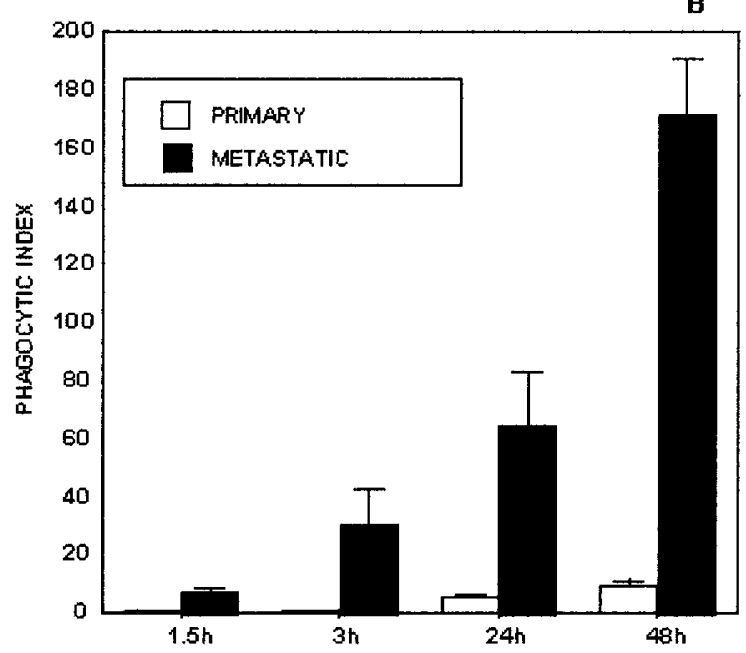

Figure 7.

Time course of phagocytic activity of human melanoma cells. A, Kinetics of melanoma cell phagocytic activity against yeast cells as evaluated by FACS analysis. Histograms are the mean \pm SEM of the percentages of either primary or metastatic melanoma cells containing the Congo Red-stained yeast particles at the various time points. B, Kinetics of melanoma cell phagocytic activity against latex beads calculated as phagocytic index (P.I.). Histograms are the mean \pm SEM of the P.I. of either primary or metastatic melanoma cells containing the latex beads at the various time points.

finding was highly consistent with a recent study showing the importance in macrophages of the linkage between actin filaments and the membrane of the secondary phagosomes through the ERMs, and particularly through ezrin, for the occurrence of efficient phagocytosis (Defacque et al, 2000). Moreover, recent findings suggest that ezrin is involved in the intracellular traffic of NK granules (Ramoni et al, 2002), which together with melanosomes belong to a lysosomal-like vesicle family (Dell'Angelica et al, 2000). The ability of cytochalasin B to entirely abrogate the phagocytic activity of melanoma cells further suggests a key role of the actin cytoskeleton in this phenomenon.

We have recently shown that specific activation of $\rho$-GTPase family proteins through bacterial toxins leads to a genuine phagocytic activity in a human epithelial cell line that normally does not endocyte or phagocyte either latex beads or apoptotic cells (Fiorentini et al, 2001). Dysregulation of the ezrin activation/phosphorylation may represent a major mechanism in promoting this potent phagocytic activity of metastatic melanoma cells, rather than the different level of expression of the ezrin protein between metastatic and primary tumors. On one hand, both recent reports (Ohtani et al, 1999, 2002; Makitie et al, 2001) and our preliminary data (not shown) did not show a clearcut difference in the levels of ezrin between human tumors with different degrees of malignancy. On the other hand, a correlation has been hypothesized between overexpression of proteins of the $\rho$-GTPase family, known as major ERM phosphorylation regulators (Yonemura et al, 2002), and tumor cell metastatic potential (Clark et al, 2000).

Our findings are highly consistent with some reports showing that phagocytic behavior is an indicator of high-grade malignancy and increased turnover in tumors of different histotypes (Banerjee and Harris, 2000; Brouwer et al, 1984; Coopman et al, 1998; Montcourrier et al, 1994). However, it is highly conceivable that the phagocytic potential of human melanocytes (Dell'Angelica et al, 2000; Koga et, 1992; Le Poole et al, 1993) underlies the potent phagocytic activity of human metastatic melanoma cells that we have shown in this study. In fact, in the present report we compare phagocytic activity of metastatic melanoma cells with the phagocytic activity exerted by professional phagocytic cells, ie, by human primary macrophages. Strikingly, results obtained did not show any significant difference between the two cell types in terms of phagocytic ability.

Phagocytic activity of human normal melanocytes has been shown using long-term assays and opsonized beads (Le Poole et al, 1993), whereas in this study plain plastic beads, apoptotic nuclei, and Congo Red-stained yeasts were used, to assess the phagocytic activity at early time points (1-3 hours). This approach has been suggested as the most suitable to compare the phagocytic activity of melanoma cells to that of professional phagocytes (Hu et al, 2000). In these experimental conditions only melanoma cells deriving from metastatic melanomas exerted a phagocytic activity comparable to that of human primary macrophages. In fact, the experiments performed at 24 and 48 hours showed that the metastatic cells increased their phagocytic activity over time, whereas the primary tumor-derived cells showed barely detectable phagocytosis, of both yeasts and latex beads, even at the later time points. However, it is highly conceivable that, given the ability of normal melanocytes to phagocyte, even though in strained experimental conditions (Le Poole et al, 1993), and the lysosomal nature of melanosomes (Dell'Angelica et al, 2000), malignant melanoma cells may hijack a physiologic activity exerted by melanocytes in normal tissues. This may include other advantages that tumor cells may acquire during malignant differentiation, such as the multivesicular body-derived exosomes (Andreola et al, 2002). 
A

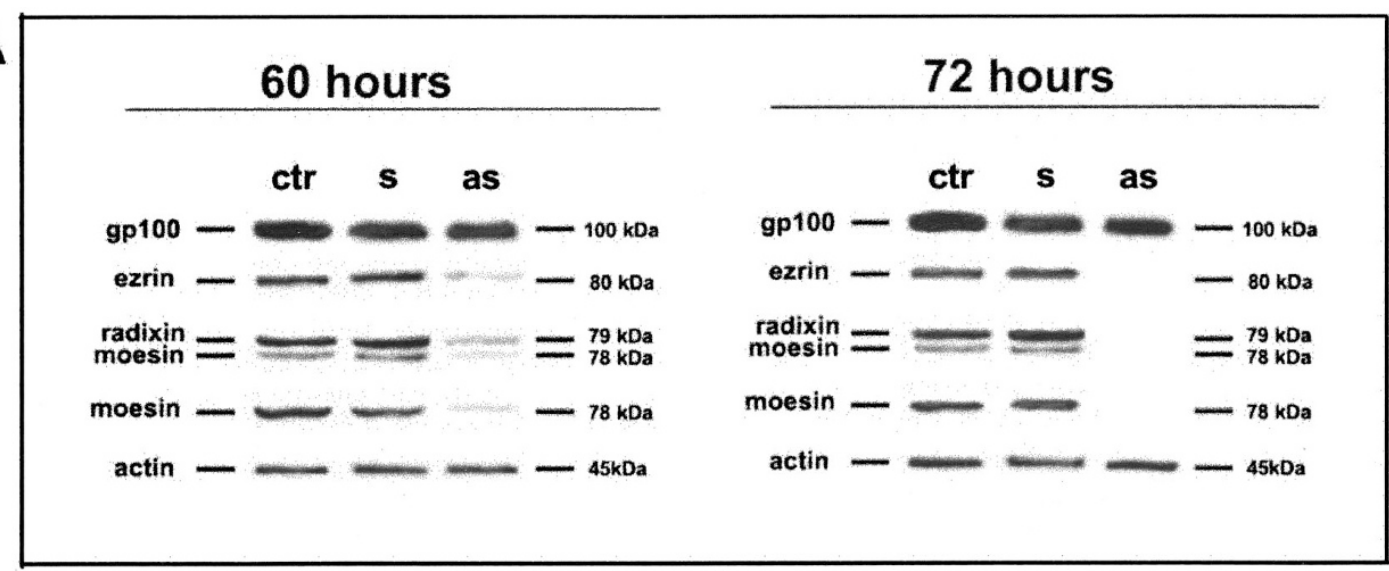

B
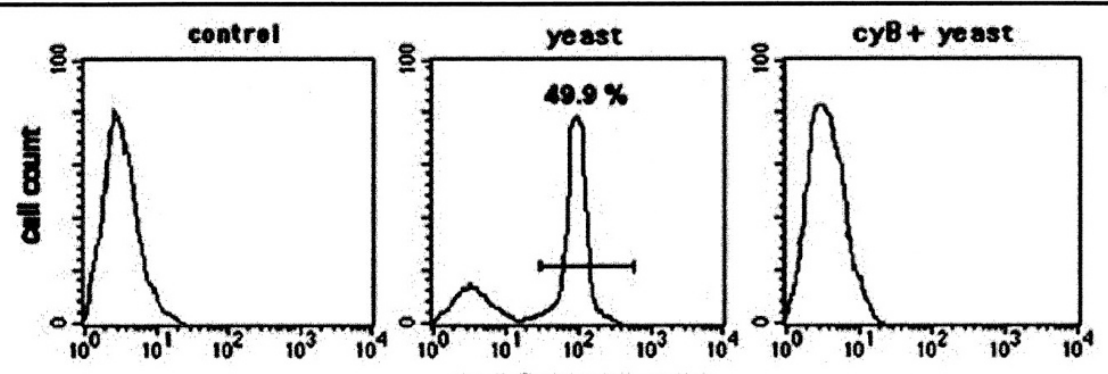

red fuorescence
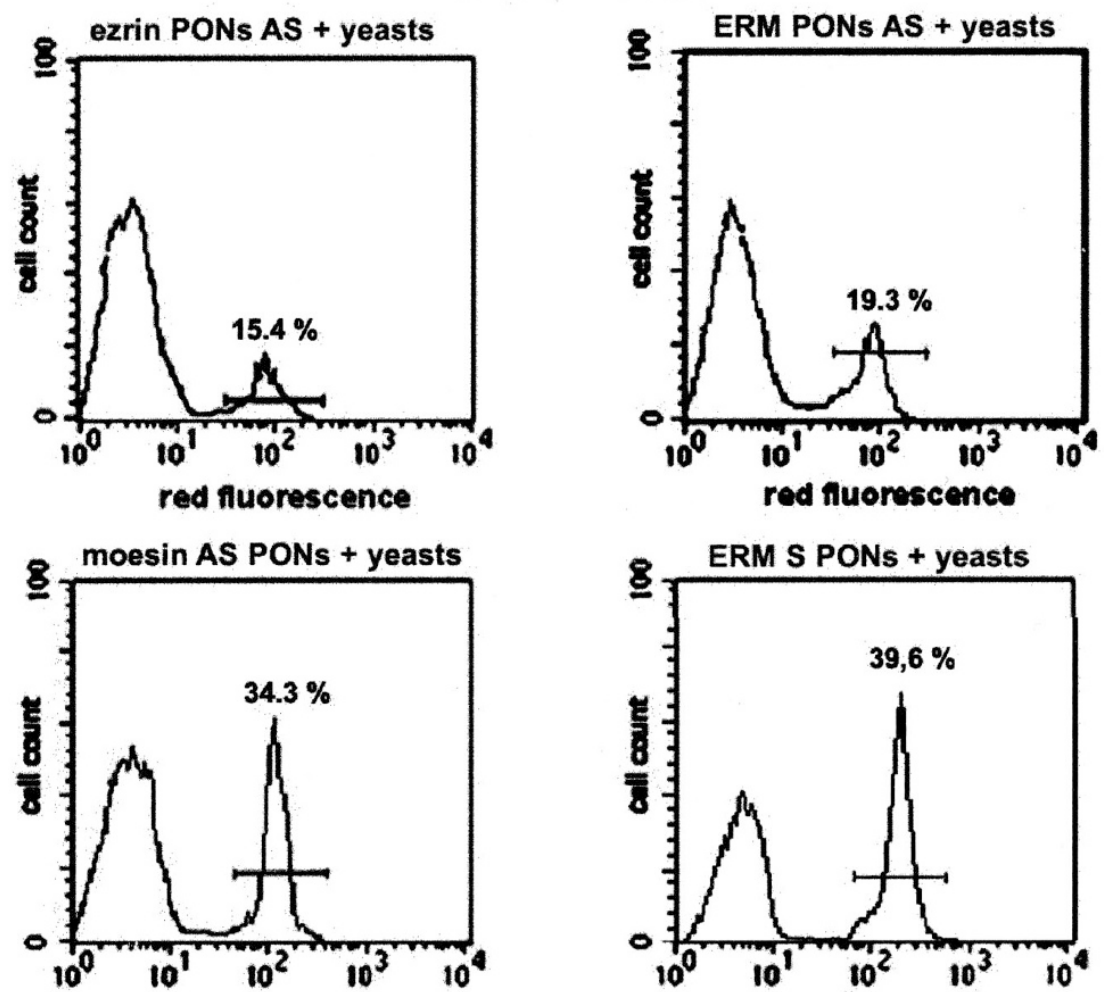

red fluorescence

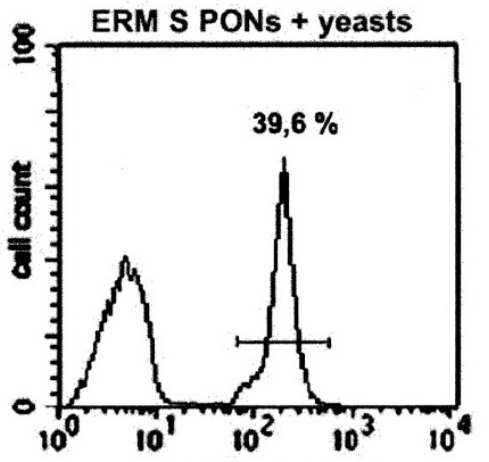

red fluorescence

Figure 8.

The role of cytoskeleton in the phagocytic activity of melanoma cells. A, Western blotting on membrane/cytoskeleton fraction of sense $(s)$ or antisense (as) phosphorothioate oligonucleotide (PONs)-treated or untreated (ctr) melanoma cells. Actin and gp-100 were used as control proteins. One of five representative experiments is shown. B, FACS analysis of the effect exerted by cytochalasin B and PONs to ERM (ezrin, radixin, and moesin) on the phagocytic activity of melanoma cells. In the upper panels, metastatic melanoma cells without yeasts, 3.30 hours after the addition of the yeasts, and the effect of cytochalasin B pretreatment on yeast internalization, respectively, are shown. In the middle panels, the effect of treatment with the antisense PONs to ezrin and a mix of the antisense PONs to all of the ERM are shown. In the lower panels, the effect of treatment with the antisense PONs to moesin and a mix of the sense PONs to all of the ERM are shown. One representative experiment is shown. 

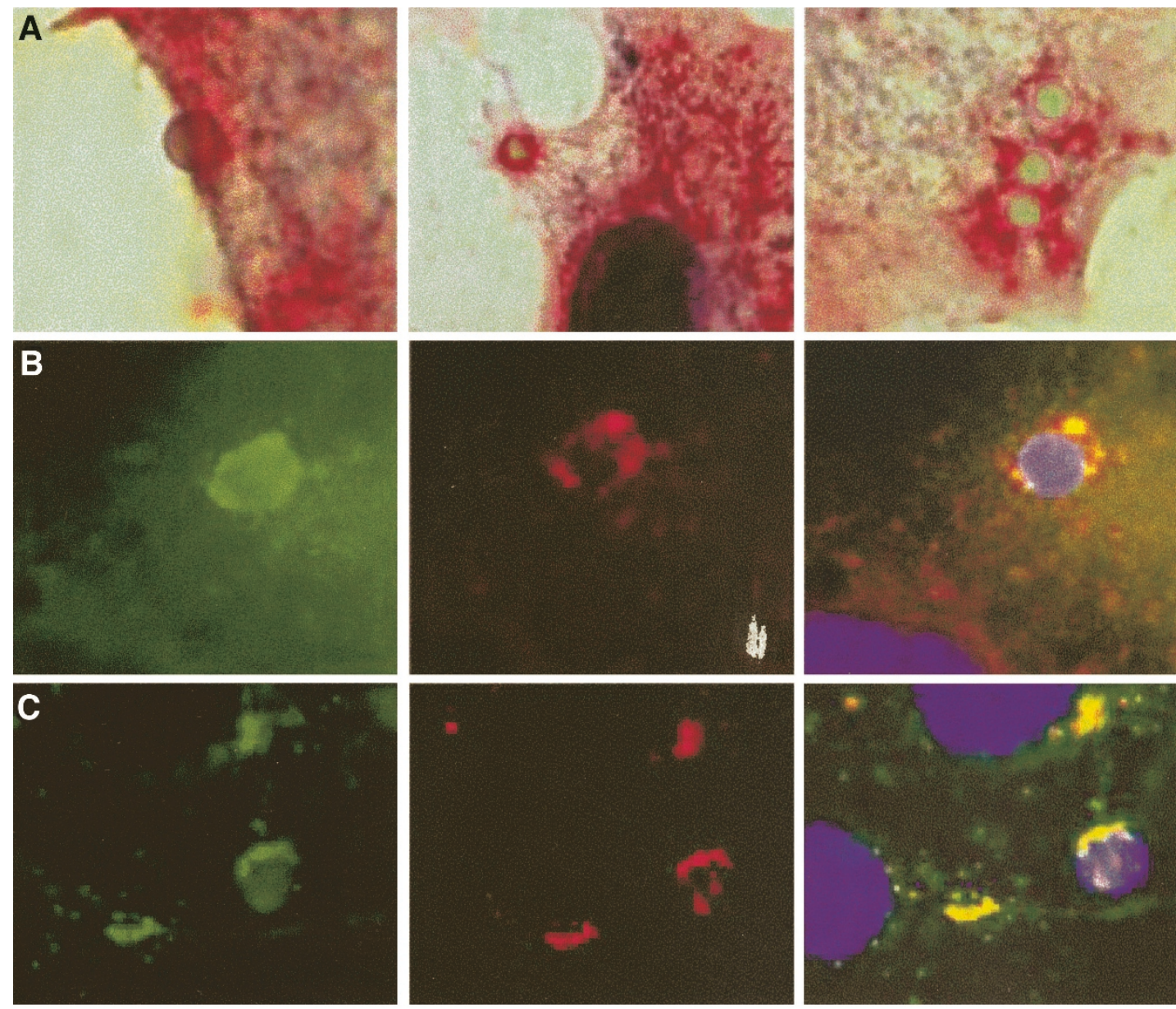

EZRIN

LAMP1

MERGE

Figure 9.

ERM localization on phagocytic vacuoles of human melanoma cells. A, Progressive internalization of latex beads in human melanoma cells stained for ezrin. Note the early process of endocytosis, where ezrin concentrate into the internal site of the endocytic compartment (left panel, magnification $\times 3500$ ), the internalization of the bead within a vacuole nicely surrounded by the ezrin staining (central panel, magnification $\times 2500$ ), and the definitive internalization of three beads outlined by the ezrin staining (right panel, magnification $\times 2500$ ). Immunophenotyping of fixed cells was performed using the PAP method. AEC was used as chromogen and Mayer's hematoxylin for the counterstaining. B, Immunofluorescence analysis of the internalization of an apoptotic cell by a human melanoma cell. Triple fluorescence was performed on fixed cells with polyclonal anti-ezrin, with mAb anti-human LAMP-1, and with Hoechst 33258. Note the colocalization (merge) of ezrin and LAMP-1 on cytoplasmic vesicles of a melanoma cell, containing an apoptotic cell (Magnification, $\times 3500$ ). C, Immunofluorescence analysis of the internalization of an apoptotic lymphocyte by a human breast adenocarcinoma cell line. Triple fluorescence was performed on fixed cells with polyclonal anti-ezrin, with mAb anti-human LAMP-1, and with Hoechst 33258. Note the colocalization (merge) of ezrin and LAMP-1 in cytoplasmic vesicles of a carcinoma cell, containing an apoptotic cell (Magnification, $\times 3500)$.

Altogether, our findings define an important mechanism that may be exploited by human melanoma, as well as by other human tumors, to invade tissues through an uncontrolled feeding of surrounding dead cells and extracellular materials. Moreover, the present study shows that the phagocytic behavior of human metastatic melanoma cells was always comparable to that exerted by human professional phagocytes, in phagocyting apoptotic cells from different human histotypes. It is therefore conceivable that melanoma cells, through phagocytosis of dead cells, may compete with the scavenging activity of both macrophages and professional APC, leading to the reduction of antigenic material to the professional APC. This mechanism may in turn interfere with the activation of the immune response against tumors, thus contributing to the development of tumor im- mune escape. This is further supported by our evidence that phagocytic activity was exerted by melanoma cells deriving from metastatic lesions, whereas cells obtained from primary melanomas did not show detectable phagocytic activity.

Because phagocytic activity was exclusively exerted by metastatic melanoma cells, we can speculate that phagocytic activity is a powerful property of highly aggressive tumors. The novelty of our data is the demonstration that this phagocytic activity does not merely account for the ability of malignant tumor cells to nibble the extracellular matrix or cell debris (Banerjee and Harris, 2000; Kuroda et al, 1999), but to actively engulf, ingest, and digest apoptotic cells. This mechanism may contribute to the typical ability of malignant tumor cells to survive in the lack of trophic supply, both in vivo and in vitro. Thus, the ex vivo 
assessment of phagocytic activity may represent a new tool in discriminating the level of aggressiveness of human malignant melanoma, as well as of malignant tumors of other histotypes. Further investigation needs to characterize the specific role of ezrin in the development of the potent phagocytic activity of metastatic melanoma cells, but our data provide clear evidence for a major role of the ezrin-mediated connection to the actin cytoskeleton in this mechanism. Data obtained with murine professional phagocytes (Defacque et al, 2000) suggest that tumor phagocytic activity may occur through the ezrin-mediated assembly of the actin filaments on the lysosomal membranes. This supports the use of new antitumor strategies aimed at inhibiting the tumor phagocytic activity, through the use of actin inhibitors or specific activators/inhibitors of the actin regulatory proteins.

\section{Materials and Methods}

\section{Cells}

Human melanoma cell lines used were as follows: (i) metastatic melanomas: Me30631, Me26258, Me14783, Me10249, Me17781, Me501, Me624.38, Me15392, Me8621 (obtained from melanomas of patients surgically resected at the Istituto dei Tumori, Milan), Me116, Me160 (kindly provided by Dr. Maio, Centro di Riferimento Oncologico, Aviano); (ii) primary melanomas: Me5810P, Me9923P, Me10538P, Me1007P, Me20842P, Me4405P (obtained from melanomas of patients surgically resected at the Istituto dei Tumori, Milan), WM904, and WM 743 (a gift from Dr. Meenhard Herlyn, Wistar Institute, Philadelphia, Pennsylvania).

Primary and metastatic melanoma cell lines were derived from histologically diagnosed primary (cutaneous) and secondary (subcutaneous, lymphonodular, or visceral) melanoma lesions, respectively, as previously described (Lupetti et al, 1996; Jonjic et al, 1992; Mortarini et al, 1991, 1992; Pietra et al, 2001; Rodolfo et al, 1988). All melanoma cell lines expressed melanoma antigens such as MART-1, gp100, and tyrosinase and members of the MAGE family. Additionally, all lines were found to bear mutations or deletions of the p16 gene (not shown). Peripheral blood mononuclear cells were isolated by FicollHypaque (Pharmacia, Uppsala, Sweden) density separation of buffy coats from healthy donors. To obtain monocytes, the peripheral blood mononuclear cell fraction was separated on 46\% Percoll (Biochrom KG, Berlin) density gradients as described (Parlato et al, 2001).

To obtain macrophages, human monocytes were cultured under the same conditions as melanoma cells but with $15 \%$ fetal bovine serum and left to differentiate for 1 week at $37^{\circ} \mathrm{C}$. To obtain dendritic cells, blood-derived monocytes were plated at a concentration of 1 to $2 \times 10^{6}$ cells/mL in RPMI 1640 (Gibco BRL, Gaithersburg, Maryland) supplemented with $10 \%$ lipopolysaccharide-free FCS. Cultures were added with granulocyte macrophage-CSF $(500 \mathrm{U} / \mathrm{mL})$ or IL-4
(25 ng/mL; specific activity, $10^{7} \mathrm{lU} / \mathrm{mg}$ ) (R\&D Systems, Minneapolis, Minnesota), as described (Parlato et al, 2001). Human U937 cell line and Jurkat lymphoblastoid $\mathrm{CD}^{+}{ }^{+} \mathrm{T}$ cells and the mouse NIH-3T3 fibroblast cell line were cultured in RPMI 1640 containing 10\% fetal bovine serum, supplemented with $100 \mathrm{IU} / \mathrm{ml}$ penicillin, $100 \mu \mathrm{g} / \mathrm{ml}$ streptomycin (Gibco), and $2 \mathrm{~mm}$ glutamine (Gibco) in a $5 \% \mathrm{CO}_{2}$ environment at $37^{\circ} \mathrm{C}$.

\section{Antibodies, Immunocytochemistry, Immunofluorescence, and Immunohistochemistry}

Antibodies. mAbs used were as follows: antiLamp-1, anti-Lamp-2, anti-CD63 (PharMingen International), anti-CD68 (Dako, Denmark), anti-ezrin (Biogenesis, United Kingdom), anti-moesin (Transduction Laboratories). Polyclonal antibodies used were as follows: anti-rabbit Rab5 and anti-goat Rab7 antibodies (Santa Cruz Biotechnology, Inc., Santa Cruz, California); and anti-ezrin, anti-moesin, and anti-radixin (Santa Cruz).

Immunocytochemistry. Melanoma cells were attached on glass chamber slides (Labtek, Naperville, Illinois), fixed and stained by immunocytochemistry using either the alkaline phosphatase anti-alkaline phosphatase (Dako, Denmark) or the peroxidase antiperoxidase (Dako, Denmark) method, in single staining, as appropriate (Parlato et al, 2001). Images were collected by a camera scanner for universal light microscopy application (AxioCam, Carl Zeiss Vision, Germany) and electronically elaborated through a modular image processing and analysis system (AxioVision, Carl Zeiss Vision) allowing electronic magnification of the acquired images and measurements of any recognizable cellular structures, as described (Andreola et al, 2002).

Immunofluorescence. Cells were fixed with $4 \%$ paraformaldehyde in PBS for 30 minutes at room temperature. After washing in the same buffer, cells were permeabilized with $0.5 \%$ Triton X-100 in PBS for 5 minutes at room temperature. For localization of ezrin and LAMP-1, samples were incubated at $37^{\circ}$ for 30 minutes with the polyclonal antibodies to ezrin and the mAbs to LAMP-1. Cells were then incubated with anti-rabbit IgG FITC-conjugate (Sigma Chemical Company, St. Louis, Missouri) or anti-mouse IgG TRITC-conjugate (Sigma) for detection of ezrin and LAMP-1, respectively. After washing, all samples were incubated for 10 minutes with Hoechst 33258 (10 $\mu \mathrm{g} / \mathrm{ml}$ ) and mounted with glycerol-PBS (2:1) and observed with a Nikon Microphot fluorescence microscope. Samples were analyzed by intensified chargecoupled device video microscopy (IVM). Images were captured by a color chilled 3CCD camera (Zeiss). Normalization and background subtraction were performed for each image. Figures were obtained by merging ezrin-FITC (green), LAMP-1-TRITC (red), and Hoechst 33258 (blue) images by using IAS 2000 software for image analysis (Deltasistemi, Milan, Italy).

Histologic and Immunohistochemical Evaluation. For histologic analysis, tumor tissues were fixed in $7 \%$ neutral-buffered formalin and embedded in paraffin 
wax. Four-micrometer-thick sections of embedded tissues were cut and stained with hematoxylin and eosin. Tunel stain was performed on formalin-fixed paraffin-embedded tissue using the Apoptosis Detection Kit (R\&D Systems).

\section{Electronmicroscopy}

For transmission electron microscopy, melanoma cells were fixed with $2.5 \%$ glutaraldehyde and postfixed in $1 \% \mathrm{OsO}_{4}$, dehydrated through graded ethanols, and embedded in epoxy resin (EPON 812). Thin sections were stained with uranyl acetate and lead citrate and observed with a Philips EM208S transmission electron microscope.

\section{Phagocytosis Assays}

Phagocytosis was assayed by adding $5 \times 10^{5}$ latex beads (Sigma) (Fiorentini et al, 2001) or UVB irradiation-induced apoptotic cells of the various origins (see below) (Kaminski et al, 1985) to Chamber slides (Falcon) containing either $5 \times 10^{4}$ human melanoma cells or $2 \times 10^{5}$ primary macrophages. The slides were incubated for 1.5, 2.5, 3.5, 24, and 48 hours at $37^{\circ} \mathrm{C}$, washed five times with PBS, and stained with Mayer's hematoxylin (BDH, England). Phagocytosis was evaluated by counting 200 melanoma cells or macrophages per well at $\times 40$ magnification. Results were expressed as phagocytic index (P.I.), which was generated by multiplying the percentage of cells containing at least one bead or apoptotic cell by the mean number of absorbed materials per melanoma cells (Hu et al, 2000).

Yeast cells were stained by adding $3 \mathrm{ml}$ of Congo Red solution, $0.87 \% \mathrm{w} / \mathrm{v}$ in PBS, to $1.5 \mathrm{~g}$ of yeast (Saccharomyces cerevisiae) (Kaminski et al, 1985). The slurry was mixed and left for 15 minutes at room temperature. Then distilled water was added to the slurry of stained yeast cells. The solution was autoclaved for 15 minutes to kill yeast cells and sterilize the solution. These cells were incubated 60:1 with either melanoma cells or primary macrophages at $37^{\circ} \mathrm{C}$ and $5 \% \mathrm{CO}_{2}$. Phagocytosis was stopped at 1.5, 2.5, 3.5, 24 , and 48 hours by washing away the excess yeast cells with PBS and adding a PBS solution containing trypsin (1.5 g/L)-EDTA (0.4 g/L). The analysis of phagocytosis was performed by spectrophotometry (Amersham, Pharmacia), evaluating the absorbance of stained yeast cells within melanoma cells or macrophages at $510 \mathrm{~nm}$. A standard curve has been prepared by using a series of standard solutions containing known concentrations of yeast cells and melanoma cells or a macrophage control. Alternatively, phagocytosis of stained yeast cells was analyzed on a FACScan flow cytometer (Becton Dickinson) equipped with a 488-nm argon laser. At least 20,000 events have been acquired. Data were statistically analyzed (Student's $t$ test) on a Hewlett Packard computer using the Lysys II Software.

\section{Antisense Oligonucleotides}

Melanoma cells were treated with ERM antisense PONs and submitted to FACS phagocytosis assay. The sequences 5'AGACGGGTCCTCCAGTCCTTC3' and 5'TACGGGTTTTGCTAG3' were chosen for ezrin/ radixin and moesin, respectively (Parlato et al, 2000). The PONs were suspended in serum-free medium and added to the culture medium every 12 hours at a concentration of $40 \mathrm{~mm}$ for 60 or 72 hours. Sense PONs of the same region were used as controls.

\section{Cell Lysis and Western Blot Analysis}

Subconfluent melanoma or macrophage cultures were pelleted and washed with PBS and then lysed in an extraction buffer (AKT buffer) containing $20 \mathrm{~mm}$ Tris$\mathrm{HCl}(\mathrm{pH} 7.5), 150 \mathrm{~mm} \mathrm{NaCl}, 10 \%$ glycerol, 1\% NP-40, and both phosphatase and protease inhibitors (phenylmethylsulfonyl fluoride $2 \mathrm{~mm}, \mathrm{Na}_{3} \mathrm{VO}_{4} 10 \mathrm{~mm}$, and $10 \mathrm{mg} / \mathrm{ml}$ of aprotinin) for 20 minutes at $4^{\circ} \mathrm{C}$. Proteins were resuspended in SDS sample buffer, denatured by boiling, and separated on $8 \%$ SDS-PAGE gel and electroblotted on nitrocellulose (Protran BA85; Schleicher \& Schuell). Lamp-1, Lamp-2, and CD63 mAbs and Rab5 and Rab7 polyclonal Abs were used at 2 $\mu \mathrm{g} / \mathrm{ml}$. Immunodetection of proteins was visualized after incubation with peroxidase anti-lg followed by the enhanced chemiluminescence method (ECL; SuperSignal West Dura Extended Substrate, Pierce, Illinois). ERM levels were detected by Western blot as described (Luciani et al, 2002).

\section{References}

Andreola G, Rivoltini L, Castelli C, Huber V, Perego P, Deho $P$, Squarcina P, Lozupone F, Lugini L, Stringaro A, Arancia G, Parmiani G, and Fais S (2002). Induction of lymphocyte apoptosis by tumor cell secretion of FasL-bearing microvesicles. J Exp Med 195(10):1303-1316.

Banerjee SS and Harris M (2000). Morphological and immunophenotypic variations in malignant melanoma. Histopathology 36:387-402.

Bretscher A, Reczek D, and Berryman M (1997). Ezrin: A protein requiring conformational activation to link microfilaments to the plasma membrane in the assembly of cell surface structures. J Cell Sci 110:3011-3018.

Brouwer M, de Ley L, Feltkamp CA, Elema J, and Jongsma AP (1984). Serum-dependent "cannibalism" and autodestruction in cultures of human small cell carcinoma of the lung. Cancer Res 44:2947-2951.

Clark EA, Golub TR, Lander ES, and Hynes RO (2000). Genomic analysis of metastasis reveals an essential role for RhoC. Nature 406:532-535.

Coopman PJ, Do MT, Thompson EW, and Mueller SC (1998). Phagocytosis of cross-linked gelatin matrix by human breast carcinoma cells correlates with their invasive capacity. Clin Cancer Res 4:507-515.

Defacque H, Egeberg M, Habermann A, Diakonova M, Roy C, Mangeat P, Voelter W, Marriot G, Pfannstiel J, Faulstich H, and Griffiths G (2000). Involvement of ezrin/moesin in de 
novo actin assembly on phagosomal membranes. EMBO $J$ 19:199-212.

Dell'Angelica EC, Mullins C, Caplan S, and Bonifacio JS (2000). Lysosome-related organelles. FASEB J 14:12651278.

DeSimone PA, East R, and Powell RD (1980). Phagocytic tumor cell activity in oat cell carcinoma of the lung. Human Pathol 11:535-539.

Fiorentini C, Falzano L, Fabbri A, Stringaro A, Logozzi M, Travaglione S, Contamin S, Arancia G, Malorni W, and Fais S (2001). Activation of Rho-GTPases by cytotoxic necrotizing factor 1 induces macropinocytosis and scavenging activity in epithelial cells. Mol Biol Cell 12:2061-2073.

Gautreau A, Louvard D, and Arpin M (2002). ERM proteins and NF2 tumor suppressor: The Yin and Yang of cortical actin organization and cell growth signaling. Curr Opin Cell Biol 1:104-109.

Hu B, Sonstein J, Christensen PJ, Punturieri A, and Curtis JL (2000). Deficient in vitro and in vivo phagocytosis of apoptotic $\mathrm{T}$ cells by resident murine alveolar macrophages. $\mathrm{J} \mathrm{Im-}$ munol 165:2124-2133.

Jonjic N, Martin-Padura I, Pollicino T, Bernasconi S, Jilek P, Bigotti A, Mortarini R, Anichini A, Parmiani G, and Colotta F (1992). Regulated expression of vascular cell adhesion molecule-1 in human malignant melanoma. Am J Pathol 141(6):1323-1330.

Kaminski NE, Roberts JF, and Guthrie FE (1985). A rapid spectrophotometric method for assessing macrophage phagocytic activity. Immunol Lett 10:329-331.

Koga S, Nakano M, and Tero-Kubota S (1992). Generation of superoxide during the enzymatic action of tyrosinase. Arch Biochem Biophys 292:570-575.

Kuroda N, Yamasaki I, Nakayama H, Tamura K, Yamamoto Y, Miyazaki E, Naruse K, Kiyoku H, Hiroi M, and Enzan H (1999). Prostatic signet-ring cell carcinoma: Case report and literature review. Pathol Int 49:457-461.

Le Poole IC, van den Wijngaard RM, Westerhof W, Verkruisen RP, Dutrieux RP, Dingemans KP, and Das PK (1993). Phagocytosis by normal human melanocytes in vitro. Exp Cell Res 205:388-395.

Luciani F, Molinari A, Lozupone F, Calcabrini A, Lugini L, Stringaro A, Puddu P, Arancia G, Cianfriglia $M$, and Fais $S$ (2002). P-glycoprotein-actin association through ERM family proteins: A role in P-glycoprotein function in human cells of lymphoid origin. Blood 99:641-648.

Lupetti R, Mortarini R, Panceri P, Sensi M, and Anichini A (1996). Interaction with fibronectin regulates cytokine gene expression in human melanoma cells. Int $\mathrm{J}$ Cancer 66(1): 110-116.

Makitie T, Carpen O, Vaheri A, and Kivela T (2001). Ezrin as a prognostic indicator and its relationship to tumor characteristics in uveal malignant melanoma. Invest Ophthalmol Vis Sci. 42:2442-2449.

Marin-Padilla M (1977). Erythrophagocytosis by epithelial cells of breast carcinoma. Cancer 39:1085-1089.

Montcourrier P, Mangeat PH, Valembois C, Salazar G, Sahuquet A, Duperray C, and Rochefort H (1994). Characterization of very acidic phagosomes in breast cancer cells and their association with invasion. J Cell Sci 107:2381-2391.
Mortarini R, Anichini A, and Parmiani G (1991). Heterogeneity for integrin expression and cytokine-mediated VLA modulation can influence the adhesion of human melanoma cells to extracellular matrix proteins. Int J Cancer 20;47(4):551-559.

Mortarini R, Gismondi A, Santoni A, Parmiani G, and Anichini A (1992). Role of the alpha 5 beta 1 integrin receptor in the proliferative response of quiescent human melanoma cells to fibronectin. Cancer Res 52(16):4499-4506.

Ohtani K, Sakamoto H, Rutherford T, Chen Z, Kikuchi A, Yamamoto T, Satoh K, and Naftolin F (2002). Ezrin, a membrane-cytoskeletal linking protein, is highly expressed in atypical endometrial hyperplasia and uterine endometrioid adenocarcinoma. Cancer Lett 179:79-86.

Ohtani K, Sakamoto H, Rutherford T, Chen Z, Satoh K, and Naftolin F (1999). Ezrin, a membrane-cytoskeletal linking protein, is involved in the process of invasion of endometrial cancer cells. Cancer Lett 147:31-38.

Parlato S, Giammarioli AM, Logozzi M, Lozupone F, Matarrese P, Luciani F, Falchi M, Malorni W, and Fais S (2000). CD95 (APO-1/Fas) linkage to the actin cytoskeleton through Ezrin in human T lymphocytes: A novel regulatory mechanism of the CD95 apoptotic pathway. EMBO J 19:5123-5134

Parlato S, Santini SM, Lapenta C, Di Pucchio T, Logozzi M, Spada M, Giammarioli AM, Malorni W, Fais S, and Belardelli F (2001). Expression of CCR-7, MIP-3beta, and Th-1 chemokines in type I IFN-induced monocyte-derived dendritic cells: Importance for the rapid acquisition of potent migratory and functional activities. Blood 98:3022-3029.

Pietra G, Mortarini R, Parmiani G, and Anichini A (2001). Phases of apoptosis of melanoma cells, but not of normal melanocytes, differently affect maturation of myeloid dendritic cells. Cancer Res 61(22):8218-8226.

Ramoni C, Luciani F, Spadaro F, Lugini L, Lozupone F, and Fais $S$ (2002). Differential expression and distribution of ezrin, radixin and moesin in human natural killer cells. Eur $\mathrm{J}$ Immunol 32(11):3059-3065.

Rodolfo M, Balsari A, Clemente C, Parmiani G, and Fossati G (1988). Tumorigenicity and dissemination of primary and metastatic human melanomas implanted into different sites in athymic nude mice. Invasion Metastasis 8(6):317-331.

Steinhaus J (1891). Ueber carcinom-einschlüsse. Virchows Arch 126:533-535.

Tauton $\mathrm{J}$ (2001). Actin filament nucleation by endosomes, lysosomes and secretory vesicles. Curr Opin Cell Biol 13:8591.

Tsang WYW, Chan JKC, and Chow LTC (1992). Signet-ring cell melanoma mimicking adenocarcinoma. Acta Cytol 37: $559-562$.

Yonemura S, Matsui T, Tsukita S, and Tsukita S (2002). Rho-dependent and -independent activation mechanisms of ezrin/radixin/moesin proteins: An essential role for polyphosphoinositides in vivo. J Cell Sci 115:2569-2580. 